\title{
Paradigma usul fikih multikultural di Indonesia
}

\author{
Moh Dahlan
}

\author{
STAIN Bengrulu \\ Email:drcdahlan@yahoocoid
}

This study aims to examine how the significance of multicultural paradigm of usul figh in social and national life which is diversity. Approach to study uses a paradigm shift in Kuhn's opinion and theoritical framework of this study uses a "static and dynamic multiculturality" in Baidoeri's opinion. The results of this study indicated that the diversity of life and religion of this nation need paradigms of multicultural opinion to create social and national life which are quiet, peaceful, tolerant as well as mutual respect and cooperation. As the largest Muslim nation, Muslims of Indonesia should have a multicultural paradigm of usilsiqhto build a fiqh opinion which is tolerant and accommodating towards differences and diversity of socio-culture, politics and religion, rather than monocultural paradigm of ushul figh that aims to formalize the Islamic jurisprudence that is exclusive and discriminatory.

\section{Keywords: Paradigm shift; multiaulturalism Usłl fiqh; Istamic junisprudence}

\section{Pendahuluan}

Hasil penelitian Thomas Santoso menunjukkan bahwa salah satu penyebab konflik terbuka antar agama di Indonesia adalah adanya paham keagamaan yang ekslusif dan keras (Arifin, 2009:13). Penelitian Thomas Santoso ini memiliki relevansi dengan pandangan Abdurrahman Wahid yang menunjukkan bahwa kelompok garis keras atau Islam transnasional mengancam eksistensi Negara Kesatuan Republik Indonesia (NKRI). Hal tersebut dikarenakan mereka memiliki ideologi diskriminatif yang menganggap setiap Muslim lain yang berbeda dari mereka sebagai kurang Islami, atau bahkan kafir dan murtad. Merekajuga melakukan infiltrasi ke masjid-masjid, lembaga pendidikan, instansi pemerintah maupun swasta dan ormas moderat, terutama Muhammadiyah dan Nahdlatul Ulama(NU), untuk menjadikannya keras 
dan kaku. Mereka berambisi menguasai Muhammadiyah dan NU karena dua ormas besar ini merupakan penghalang agenda politik mereka (Wahid, 2011: 146-147).

Untuk mengantisipasi melebarnya paham keagamaan yang ekslusif dan diskriminatif tersebut perlu dirumuskan gagasan baru yang bisa mengantarkan bangsa yang religius ini bisa hidup damai dan toleran (Schumann, 2004: 58) serta saling menghargai di antara sesamanya, terutama kaum Muslim sebagai mayoritas. Gagasan baru yang diperlukan bagi kaum Muslim itu adalah pembangunan paradigma ijtihad fikih yang dapat menafsirkan kasus-kasus hukum yang dijelaskan secara rinci dan yang tidak dijelaskan secara rinci dalam al-Qur'an dan Sunnah berkaitan dengan kepentingan kemajemukan hidup masyarakat dan bangsa (Abdullah, 2000: 336). Pembangunan paradigma ijthad fikih tersebut diyakini penting. Sebab, gagasan-gagasan pembaruan fikih yang dilakukan oleh para ulama usul fikih masa lalu tidak mampu menyelesaikan kasus-kasus hukum fikih seperti status kewarganegaraan Non-Muslim, kaum perempuan dan masalah bentuk negara (An-Na'im, 1990: 84-86). Bahkan hasil-hasil ijtihad ulama usul fikih masa lampau yang telah dibakukan perlu dikritisi kembali dengan melakukan pergeseran paradigma -meminjam istilah Thomas S K hun (1970:147149) - agar ajaran hukum fikih mampu menjawab berbagai problem kemajemukan masyarakat dan bangsa ini (Minhaji, 2004: 33-34).

Paradigma ijtihad fikih yang dimaksud tersebut adalah paradigma usul fikih multikultural (Kurzman, 2001: 485 dan Barton, 1999: 334). Secara historis, paradigma ijtihad fikih ini pada dasarnya telah digariskan oleh Nabi Muhammad saw dengan meletakkan Sunnah-nya sebagai penafsir dan pelaksana praktis dari ajaran hukum kitab Suci al-Qur'an yang telah berhasil mengakomodir kemajemukan tatanan sosial-budaya dan politik kaum Muslim dan non-Muslim di Madinah, (Rachman, 1995: 209) yang dikenal dengan "Piagam Madinah". Bahkan Piagam Madinah menjadi eksperimen dalam membangun tatanan sosial-politik yang diperintahkan bukan oleh kemauan pribadi, melainkan secara bersama-sama dan berdasarkan kesepakatan warga masyarakat yang majemuk, baik dari segi golongan maupun agama (Rachman, 1995: 590). Eksperimen seperti Piagam Madinah ini juga dilanjutkan oleh Umar bin Khattab ketika ia harus mengakomodir kepentingan warga masyarakat non-Muslim setempat dan kepentingan kaum Muslim pada kasus harta rampasan perang (An-Na'im, 1990: 28). D emikian juga Utsman bin Affan menetapkan hukum-hukum fikih bukan hanya 
berdasarkan bunyi nas, tetapi juga berdasarkan kepentingan kemajemukan sosial-budaya masyarakat (Siry, 1996: 45).

Gagasan-gagasan pembangunan fikih yang dilakukan oleh Nabi dan para sahabatnya menunjukkan arti penting penghargaan dan kerjasama dalam kehidupan sosial-budaya dan politik yang majemuk. Gagasan-gagasan pembangunan fikih ini dapat didukung oleh hasil penelitian Chanchal Kumar (2011: 3) yang menunjukkan bahwa multikulturalisme bukan hanya sebuah pernyataan faktual, tetapi juga mengandung nilai universal, yaitu nilai penghargaan terhadap keragaman budaya dan menempatkan sebuah masyarakat yang berbeda dalam suatu komunitas yang membentuk identitas bersama walaupun mereka tetap mempertahankan asal budayanya. Oleh sebab itu, kajian ini bertujuan menguji bagaimana signifikansi paradigma usul fikih multikultural dalam kehidupan kemasyarakatan dan kebangsaan yang majemuk.

\section{Kerangka teori}

Secara harfiah, kata fighberarti "paham yang mendalam". Jika "paham" dapat digunakan untuk hal-hal yang bersifat lahiriyah, maka fikih berarti paham yang menyampaikan ilmu lahir kepada ilmu batin (Syarifuddin, 2009: 2 dan al-Q ardlawi, 2001: 21). Secara istilah, ada sejumlah definisi di kalangan fuqaha' di antaranya: Petama, Amir Syarifuddin menyebutkan bahwa fikih adalah ilmu tentang hukum-hukum shara' yang bersifat amaliah yang digali dan ditemukan dari dalil-dalil yang tafsili. Keelua, Al-Amidi mengatakan bahwa fikih adalah ilmu tentang seperangkat hukum-hukum syara' yang bersifat funu'yahyang berhasil didapatkan melalui penalaran atau istidlal (Syarifuddin, 2009: 3-4).

Usul fikih adalah ilmu yang membahas tentang sumber pokok dan metode pengambilan penetapan hukum Islam, sedangkan definisi lainya menyebutkan bahwa usul fikih adalah ilmu tentang kaidah-kaidah yang membawa kepada usaha merumuskan hukum syara' dari dalilnya yang terinci. Untuk menetapkan dan merumuskan pemecahan hukum dari sumber dan dalil al-Qur'an dan Sunnah perlu dilakukan ijtihad, sedangkan ijtihad adalah upaya sungguhsungguh untuk memahami dan menafsirkan sumber dan dalilnya (Djamil, 1997: 14; D onohue dan Esposito, 1995: 325; Syarifuddin, 2009: 41). 
Kata "multikultural" merupakan gabungan dari kata milty(banyak) dan alture(budaya). Secara sederhana, "multikultural" dapat diartikan sebagai suatu paradigma tentang kesetaraan semua ekspresi budaya (Mustato', 2008). D alam tradisi keilmuan, multikulturalitas memiliki dua orientasi, yaitu Petama, multikulturalitas statis yang berpandangan mengenai keragaman yang bersifat fragmentatif, sehingga keragaman itu menjadi serpihan budaya yang berjalan sendiri-sendiri sesuai dengan spesifikasi masing-masing. Masing-masing anggota kelompok berupaya mempertahankan identitas-identitas partikularitasnya. Keetua, multikulturalitas dinamis yang berpendapat bahwa dalam beragam budaya atau tradisi terjadi interkulturalitas. Identitas baru yang dikonstruksi tidak lagi terkungkung oleh kondisi lokal tertentu, tetapi menekankan kolektifitas identitas lokal dari masing-masing kelompok identitas yang telah mengalami kondisi fragmentasi (Baidoeri, 2009: 13-15).

\section{Problematika kemajemukan hidup bangsa Indonesia}

Dalam kehidupan masyarakat yang majemuk telah terjadi tuntutan tersendiri untuk membangun tatanan kehidupan yang rukun, damai, toleran dan saling menghargai. Hal ini didasari oleh beberapa alasan. Petama, secara kodrati, Allah menciptakan manusia dalam keanekaragaman budaya, sehingga pembangunan manusia perlu memperhatikan keanekaragaman budaya tersebut. D alam konteks Indonesia juga menjadi keharusan bahwa pembangunan manusia Indonesia semestinya berwawasan multikultural, karena negeri ini berdiri tegak di atas keanekaragaman budaya, baik dalam budaya beragama, berpolitik maupun berekonomi. Keetua, dalam banyak kasus konflik sosial yang bernuansa SARA (suku, agama, dan ras) pada dasawarsa terakhir ini ditengarai berkaitan erat dengan masalah kebudayaan. Dalam banyak hasil penelitian disebutkan bahwa salah satu penyebab utama munculnya konflik ini adalah akibat lemahnya pemahaman dan pemaknaan tentang konsep kearifan budaya. Menurut al-Q adrie, berbagai konflik sosial di negeri ini disebabkan oleh kurangnya kemauan untuk menerima dan menghargai pendapat, karya dan jerih payah orang lain, kurangnya kesetiakawanan sosial, dan tumbuhnya sikap egois serta kurangnya kepekaan sosial. Keiga, pemahaman terhadap multikulturalitas merupakan kebutuhan bagi bangsa untuk menghadapi tantangan global agar siap menghadapi arus budaya luar dan mampu menyatukan seluruh elemen bangsa yang terdiri dari berbagai macam budaya, 
sehingga ancaman disintegrasi dan konflik bangsa dapat dihindarkan. Samuel P. Huntington juga menyebutkan bahwa terjadinya berbagai konflik sosial dan etnis di berbagai belahan dunia antara lain disebabkan oleh adanya perbedaan kebudayaan (Rifai, 2006).

A hmad Faisol (2010: 67-68) menunjukkan bahwa adanya kekerasan yang dilakukan atas nama agama biasanya muncul akibat adanya pola pemahaman keagamaan yang skriptural, yaitu pemahaman yang hanya bersandar kepada teks dan mengabaikan konteksnya. Pemahaman seperti ini melahirkan sikap fanatik dan militan yang berakibat pada pandangan bahwa hanya golongannya sendiri yang benar. Dengan klaim seperti ini, paham ini lalu berusaha mempertahankannya walaupun harus dengan kekerasan demi mempertahankan identitasnya.

Dalam hal konflik agama, Thomas Santoso menyebutkan bahwa terjadinya tindak pengrusakan gereja di Situbondo disebabkan oleh adanya pemahaman keagamaan yang membenarkan tindakan tersebut. Di kalangan sebagian kaum Muslim berkembang pemahaman keagamaan yang eksklusif yang sering mengkritik keberadaan agama lain. Penelitian Fatima Husein juga menunjukkan adanya paham eksklusif di kalangan sebagian elite Muslim yang kemudian melahirkan sikap yang sering mengkritik paham non-Muslim. Paham ini tidak hanya berkembang di kalangan sebagian elite Muslim, tetapi juga di kalangan menengah dan akar rumput. Paham seperti ini mempengaruhi cara penerimaan terhadap agama lain. Walaupun agama bukan satu-satunya penyebab konflik dan kekerasan, tetapi masih ada hal lain yang mempengaruhinya, misalnya persoalan ekonomi yang juga turut memperkeruh suasana relasi antar umat beragama (Arifin, 2009: 13-14).

Pada masa O rde Baru, dengan slogan "persatuan" dan "kesatuan" yang dikawal oleh militer, pemerintahan Soeharto berusaha untuk menghapus segala potensi konflik suku, agama, ras dan antar golongan (SARA). Namun, ketika pemerintahan Soeharto jatuh, maka benih-benih konflik yang terpendam bertahun-tahun kemudian muncul ke permukaan yang kemudian berakhirdengan kerusuhan Mei 1998 di Jakarta. Konflik horizontal yang disebabkan SARA tersebut terjadi karena masyarakat Indonesia yang heterogen baik dari segi suku, agama, ras maupun golongan. Contoh konflik antar suku yang terjadi adalah perang antara suku di papua beberapa bulan yang lalu, konflik yang bernuansa agama terjadi di Ambon dan Poso (Islam Vs Kristen) atau antara umat dalam satu agama seperti antara Islam dan 
Ahmadiyyah atau antara Sunni dan Syi'ah. Konflik antar Ras, seperti perang antara etnis Melayu dan Dayak di Sambas (Baraja, 2011).

Salah satu upaya untuk mengatasi hal-hal itu adalah dengan merumuskan paradigma berpikir multikulural. Paradigma multikultural adalah paradigma berpikir yang bisa menghormati, tulus dan toleran terhadap keanekaragaman budaya yang berkembang di kalangan masyarakat. Tidak seperti paradigma monokultural yang mengabaikan keunikan dan pluralitas yang telah menyebabkan terkuburnya sikap kritis dan kreatif. Karena itu, pola hidup bangsa saat ini harus dipupuk agar bisa mempertajam rasa kepekaan dan solidaritas hidup bersama antara pemeluk agama.

Usaha-usaha membangun kebersamaan berdasarkan kehidupan praktis dan pengalaman keagamaan sehari-hari perlu dilandasi gagasan metodologis yang memadai untuk mendukung pembangunan hubungan antara umat beragama yang plural di negara ini, baik dari segi ras, etnis, bahasa maupun agama. Hal ini perlu dilakukan untuk menghindari loyalitas hanya pada pandangan yang dimiliki dan lahir dari kelompoknya dan menafikan (gagasan yang lahir dari) kelompok lain. Al-Qur'an juga melarang kaum Muslim untuk bersifat melampaui batas itu sebagaimana dinyatakan berikut:

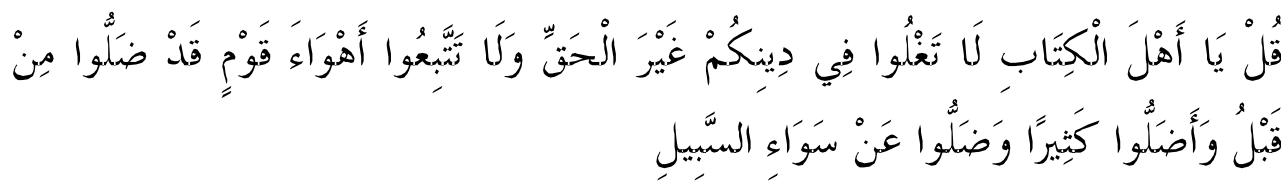

Katakanlah, wahai ahlul kitab janganlah kamu beldeih-ldihan (mdampaui batas) dengan cara tidak benar dalamagamami danjanganlah kamumengkuti hava nafu orangforangyangtdahsesat dahulunya danmedkatdahmenyesatkankebanyakan (manusia) danmedka tesesat dari jalanlunus (Q S. al-Ma'idah [5]: 77).

Kata al-ghuluw(melampaui batas) menjadi dasar pijak kaum Muslim untuk menghindari sikap berlebih-lebihan. Sebab, sikap berlebihan ini sering menyebabkan seseorang tersesat dan menyesatkan diri, bahkan tidak jarang menyebabkan berbagai masalah. D alam bahasa Arab disebutkan dengan tatłamuf yang berkonotasi makna radikal, ekstrim dan berlebihan. D i samping itu juga perlu menghindari lahimya gagasan yang tidak berlandaskan pemikiran yang matang (Abdullah, 1996: 5-8 dan Hanafi, 2009: 3). Salah satu persoalan krusial dalam kehidupan religius bangsa Indonesia adalah pemikiran mayoritas religius bangsa Indonesia 
yang beragama Islam, yakni paradigma usul fikih yang perlu selalu diperbarui agar terbangun pola pikir dan amalan praktis kaum Muslim yang bisa menghormati, tulus dan toleran terhadap keragaman budaya, agama dan hal-hal lain.

\section{Pergeseran paradigma usul fikih}

\section{Sumberfikihmondkultural danmultikultural}

'Abd al-Wahhab Khallaf mengatakan bahwa nash al-Q ur'an seluruhnya bersifat qathli baik dari sisi turun, ketetapan maupun penukilannya dari Nabi Muhammad saw. pada umatnya. Nash al-Q ur'an diturunkan Allah melalui malaikat Jibril pada Nabi untuk disampaikan pada umat manusa tanpa ada perubahan dan penggantian sedikit pun (Khallaf ,1978: 34, D ahlan, 2006, dan An-Na'im, 1990: 18).

Nash al-Q ur'an terdiri atas dua bagian: Pertama, qat,tlal-dilalahadalah nash yang mempunyai makna yang jelas dan tidak menimbulkan táwilłserta tidak ada jalan untuk dipahami selain dari makna yang jelas itu, seperti nash al-Q ur'an yang menjelaskan bagian warisan laki-laki setengah dari jumlah keseluruhan (QS. An-Nisa`[4]: 12). Kedua, zhami al-dlalahadalah nash al-Qur'an yang memiliki suatu makna tertentu, tetapi maknanya masih menimbulkan ta'wil atau dapat diubah dari makna asalnya pada makna lain, seperti ayat al-Qur'an yang menjelaskan masa 'iddahperempuan yang dilafadzkan dengan kata quûu (QS. Al-Baqarah [2]: 228) yang bisa bermakna "suci" dan "haid". D emikian juga dengan al-Sunnah sebagai sumber kedua,

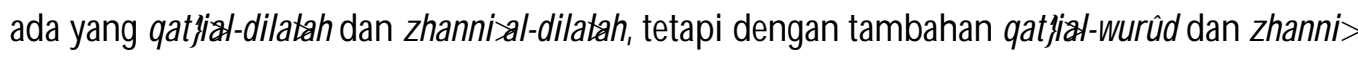
al-uruûd(Khallaf , 1978: 35 dan 42). Sesuai dengan pendapat Khallaf itu, fuqaha' monokultural - seperti Imam Asy-Syafi' i $>$ di dalam memahami qat,jal-dilalahdan zhami di-dilalahmenyatakan bahwa qat,ial-dlalahadalah nash yang tidak mempunyai makna lebih dari satu, sedang zhami > al-dilalıh adalah nash yang mempunyai makna lebih dari satu (Fanani, 2001: 441-442, alJassas, 1993: 5-6, dan al-Zukhaili, 1986: 1052-1054).

Sementara itu, fuqaha' multikultural berpendapat bahwa yang qat,jal-dlalahadalah nash yang universal atau nash yang mengandung nilai-nilai kemanusiaan sebagai ukuran untuk membangun budaya kesetaraan dan kebersamaan dalam kehidupan budaya manusia yang plural seperti ayat-ayat tentang keadilan, sedangkan nash yang zhammi al-dilalah adalah nash yang mempunyai makna jelas dan rinci yang seringkali bersifat ekslusif dan diskriminatif 
terhadap non-Muslim dan perempuan, seperti ayat-ayat tentang hak non-Muslim, hak waris dan poligami (An-Na'im, 1997: 49 dan An-Na'im dan Deng, 1990: 358-361).

\section{Paradigmaijtihadfikihmonkultural danmultikultural}

Secara historis, hukum fikih lahirnya tidak lepas dari perdebatan peran budaya dan nash sejak masa sahabat, yaitu antara Umar ibn al-Khattab dan para sahabat Nabi lainnya dalam masalah bagian mallaf dan pembagian harta rampasan perang. Umar berpijak pada kepentingan kesejahteraan dan budaya masyarakat setempat, sedangkan para sahabatlainnya berpegang teguh bunyi nash al-Q ur'an dan Sunnah yang telah menegaskan aturan hukum bagian mallafdan pembagian harta rampasan perang tersebut bagi yang berhak. Perdebatan antara peran budaya dan nash terus berlanjut di kalangan ulama fikih hingga dewasa ini (K hallaf, 1978: 98-99).

Perkembangan perdebatan fikih di dunia Islam, khususnya di Indonesia, juga tidak lepas dari masalah peran nash dan budaya (Zahra, 1999: 335 dan Nafis, 1995: 541). Tarik-menarik antara peran nash dan budaya muncul karena adanya tuntutan kepentingan dan kemajemukan budaya masyarakat, seperti kepentingan memelihara hak-hak kaum marginal dan non-Muslim. D emikian juga munculnya paradigma usul fikih mutltikultural -yang akar historisnya dari ijtihad fikih Umar bin Khattab- dilatarbelakangi oleh keberagaman kepentingan dan budaya masyarakat (Baso, 2000: 125).

Perbedaan porsi dalam menggunakan peran nash dan budaya tersebut telah mempengaruhi pembaruan fikih yang terbagi menjadi dua paradigma: Petama, paradigma usul fikih multikultural yang berusaha membuat kaidah dan hukum fikih sesuai dengan kepentingan budaya masyarakat. Begitu pentingnya nilai budaya manusia, sehingga aparapayangdilihatdeh umat Islamsdbagai suatu yangbaik, maka yangdenikian d sis Allah adklah baik (Syarifuddin, 2009: 400 dan al-Zukhaili: 1986: 82-803). Ijtihad dapat dilakukan hingga nash-nash alQ ur'an yang dianggap qath 1 ' s seperti persoalan waris dan hubungan antara agama, bukan hanya nas-nas złani saja (Kurzman, 2001: 484-503). Karena kepentingan budaya bangsa yang bersifat beragam itu dinamis, maka tinjauan mengenai kebenaran bagi paradigma ini bersifat plural, tidak tunggal. 
Kedua, paradigma usul fikih monokultural yang meletakkan nas-nas al-Q ur'an dan Sunnah sebagai dasar pijaknya dalam menjawab masalah baru, dan akal dianggap tidak mampu menafsirkan nas-nas al-Q ur'an dan Sunnah yang jelas dan rinci. D emikian juga budaya tidak memiliki peran strategis dalam menumuskan ketentuan fikih (Hasan, 1970: 180 dan Minhaji, 2001: 247). Karena itu, paradigma ini tidak menafsirkan nas-nash al-Qur'an dan Sunnah yang sudah memiliki ketentuan jelas dan rinci seperti nas-nas tentang waris dan hukum potong tangan, sehingga ukuran mengenai kebenaran bagi paradigma ini bersifat tunggal (Al-Syafi'i, t. th: 560 dan Khalaf, 1978).

\section{Pdakuijtihadfikih(mjitahid) mondkultural danmiltikultural}

Ijtihad merupakan usaha yang sungguh-sungguh dari seorang mijtahiddalam menemukan hukum-hukum sharifal-Shawwaf, 1993: 450 dan Dahlan, 2009: 141-144). Dalam melakukan upaya pembaruan fikih, terdapat tiga tingkatan mijtahid Pertama, mijtahidal-madhabadalah seorang mijtahid yang mengikuti (yuqallidu) teori ijtihad dari salah satu imam madzhab, sedangkan produk hukumnya (boleh) berbeda dengan hasil pendahulunya. Sebagai konsekuensinya, mijtahidal-madhab harus mengetahui hukum-hukum dan dalil-dalil yang berlaku di kalangan madzhabnya. Kedua, mijtahidal-masalahadalah seorang mitahidyang boleh melakukan ijtihad dengan hanya berbekal pengetahuan yang berhubungan dengan satu persoalan yang akan dipecahkan tanpa harus mengetahui persoalan lainnya yang tidak memiliki hubungan. Karena itu tidak ada syarat dan teori tertentu yang diharuskan bagi seorang mijtahiduntuk mengikuti salah satu teori ijtihaddari salah satu pendapat-pendapat madzhab, bahkan dalam memecahkan suatu persoalan, ijtihadbisa dilakukan hanya dengan mengetahui sebagian pengetahuan shar'i dan pengetahuan bahasa yang mendukung pemahaman nash syar'i itu. Selain itu, produk hukumnya boleh berbeda dengan pendapatpendapat sebelumnya. Ketiga, mjitahidal-mitlaqadalah seseorang yang memiliki kemampuan mencetuskan teori dan hukum-hukum sjari -Sebagai konsekuensinya, mitahidal-mitlaqharus mengetahui dalil-dalil samiiyjahyang menjadi dasar dalam membuat kaidah-kaidah dan hukumhukum. Hal ini meliputi al-Q ur'an, Sunnah, ijma'steori jamu tarjihłdan ta'arud Selain itu, ia juga harus mengetahui bahasa Arab, petunjuk-petunjuk lafazh dan unsur sastranya. Meskipun demikian, mijtahid al-mitljaq tidak harus mengetahui seluruh nash shar'i dan mampu 
mencetuskan berbagai hukum, sebab ia bisa jadi mencapai tingkatan ijtihadal-miljaqdalam beberapa persoalan hukum, tetapi pada persoalan hukum lain tidak sampai tingkat ijtihadalmitlaq. Dalam konteks ini dilakukan pembagian ijtihad dalam artian sejauhmana tingkat kemampuan untuk mendalami sebagian dalil-dalil shar'i secara utuh hingga pada dalil-dalil yang tampaknya kontradiksi, bukan dalam arti pembagian bab-bab fikih seperti mengetahui satu bab fikih dan tidak mengetahui satu bab fiqh lainnya. Pembagian ijtihad hanya berlaku dalam hubungannya dengan kemampuan istinbaty bukan pembagian bab-bab fikih. Di luar tiga hal tersebut adalah masuk kategori muqallid yang tindakannya sering disebut “taqlid”. (Al-Shawwaf, 1993: 453-455 dan Zahrah, 1997: 389-399).

Salah satu contoh gagasan dalam melakukan ijtihad secara ideal adalah ijtihad yang dilakukan Umar yang menempatkan gagasan fikihnya yang berbasis kultural, kepentingan penduduk setempat, dalam masalah harta rampasan perang (Dahlan, 2009: 148-149).

Contoh penting tentang upaya ijtihad dalam persoalan yang telah ditunjuk langsung oleh teks secara jelas dan rinci (dear and deinitetexts) dijumpai di dalam penolakan 'Umar untuk membagikan tanah rampasan perang selama penaklukan di Irak dan Syiria sebagai bagian dari ghama:m(rampasan perang) kepada tentara Muslim yang ikut bertempur, yang ditunjuk oleh teks al-Qur'an 59: 6-10. Ketika ditentang oleh mereka yang bersikukuh dengan pendapat bahwa Nabi telah membagi tanah rampasan perang selama hidupnya, Umar menguatkan penolakannya dengan mengikuti ayat-ayat al-Qur'an seperti yang ditafsirkan dan diterapkan (dalam sunnah, pen.) Nabi (Umarjustified hisrefusal tofdllowthe Qur'anicveses as interpreted and applied by theProphe). Alasannya, kalau hal itu dilakukan, maka akan menguras sumber pembiayaan negara yang penting yang dibutuhkan untuk membangun tentara guna mempertahankan wilayah Negara (An-Na'im, 1990: 28).

Penjelasan tersebut menunjukkan bahwa pemahaman dan kebijakan 'Umar mampu mengakomodasi pluralitas kepentingan masyarakat setempat, sehingga ia dapat mengamalkan pesan livingtradition dari Nabi, yang berarti mengikuti Sunnah Nabi dalam wujud tindakan baru yang sudah mengalami theautonomisation fadion-meminjam istilah Paul Ricoeur (1982: 206). Kebijakan 'Umar ini tidak boleh dianggap sebagai masalah kasuistik yang terpisah dari proyek pembangunan usul fikih baru. Alasannya, kaum Muslim kontemporer juga memiliki hak yang sama untuk melakukan tindakan itu, yakni ijtihad sebagaimana yang dilakukan 'Umar walaupun menyangkut masalah yang sudah diatur oleh nash al-Qur'an dan Sunnah secara jelas dan rinci. 
Imam Syafi'i sebagai Imam Madzhab yang mengambil jalan tengah antara rasionalis dan tradisionalis telah berhasil menyusun ilmu usul fikih secara sistematik yang berwawasan budaya lokal dan kepentingan masyarakat setempat, sehingga ia banyak melahirkan beragam fatwa hukum fikih yang secara umum dapat dikategorikan ke dalam qauk qadimdi Irak dan qaw jadiddi Mesir. Munculnya qawk qadimdan qawk jadidmenjadi bukti nyata bahwa gagasan usul fikih Imam Syafi'i itu bukanlah rentetan perkembangan kematangan pemikirannya secara personal saja, tetapi juga sebagai suatu refleksi dari kehidupan sosial masyarakatnya yang beragam (Sirry, 1996: 100-107 dan 142).

Secara umum, paradigma usul fikih Imam Syafi'i tersebut cocok dengan budaya masyarakat Indonesia - dengan beberapa pengecualian-karena wawasan fikihnya telah memberikan contoh bagaimana hukum fikih bisa bergaul dan mengisi kebudayaan setempat, sehingga ketentuan fikihnya menjelma menjadi qawł qadimndan qawkjadid Apalagi fikih yang diajarkan di Indonesia Nusantara adalah kebanyakan fikih yang berwawasan budaya, sehingga penyebaran ajarannya pun tidak melalui jalur militer dan kekerasan, tetapi melalui jalur pendidikan, kesenian, ekonomi dan perkawinan yang kemudian lambat laun menyebar ke berbagai pelosok Nusantara. Ajaran fikih Nusantara tidak selalu tampil dalam bentuk legalformal, melainkan justru banyak sebagai cara ibadah dan pengajian kitab-kitab kuning sebagaimana banyak dilakukan di sejumlah Pesantren Jawa hingga sekarang. Adanya sejumlah tokoh besar sufi yang telah berjasa menyebarkan Islam di Nusantara seperti Ar-Raniri, Abdur Ra'uf Singkel, Hamzah al-Fansuri dan tokoh legenda Syekh Siti Jenar dan lawannya, para Wali Sanga, menjadi bukti nyata bahwa ajaran (fikih) Islam di Nusantara terbangun secara dialektis antara norma-normanya dengan kebudayaan setempat (Wahid, 2001: 154-155).

Kebetulan sekali madzhab fikih yang berkembang di sini dulu adalah madzhab Syafi'i, yang dalam usul fikihnya mencantumkan cara-cara menyerap hukum adat ke dalam hukum fikih (melalui perangkat al-adatmihłkkamat).... Beberapa pepatah menunjukkan kedudukan penting dari hukum fikih, seperti pepatah "adat bersandi syara' dan syara' bersandi Kitabullah" di masyarakat Minangkabau dan "hukum bak kata memeihumdan adat bak kata Syah Kuala" di lingkungan Kesultanan Aceh (Wahid, 2001: 156).

Paradigma usul fikih multikultural di sini selain melakukan upaya menyusun rumusan keilmuan hukum fikih sesuai dengan kepentingan budaya masyarakat yang majemuk secara 
dinamis, bukan fregmentatif, juga bersedia mengakui hukum-hukum fikih yang terserap dalam budaya lokal tetap dalam lokalitasnya. D engan demikian, ada persamaan paradigma usul fikih ini dengan beberapa tambahan dari konsep "pribumisasi Islam-nya" Abdurrahman Wahid (Baso, 2000: 125).

\section{Menuju paradigma usul fikih multikultural}

Ajaran (fikih) Islam menjadikan rujukan nilai, pengetahuan dan tindakan bagi kaum Muslim untuk berta'aruf dengan kelompok lain dalam masyarakat yang berbeda, baik dari segi agama, sosial maupun budaya. Ajaran fikih ini perlu ditransformasi ke dalam kerangka kehidupan kaum Muslim Indonesia untuk menghadapi berbagai ancaman konflik dan disintegrasi dalam kehidupan berbangsa (Fadjar, 2007: 3).

Paradigma usul fikih multikultural di sini hadir untuk memproduk hukum-hukum fikih yang aspiratif dan akomodatif terhadap pluralitas kepentingan kebangsaan, sehingga seluruh anak bangsa mendapatkan posisi yang setara tanpa membedakan ras, agama, jenis kelamin ataupun keturunan, disamping adanya pengakuan terhadap keragaman "budaya yang sahih" (K hallaf, 1978: 79-80). Paradigma usul fikih multikultural ini berdasarkan al-Q ur'an yang menyatakan:

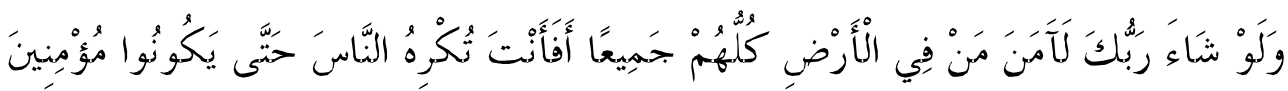

Danjikalau Tuhanmumenghendaki, tentulah beimansemua crangyangdi mikabumi sdunuhnya. Makaapakahkamu(hendkk) memaksamanusiasupaya medkammjjadi arangforangyangberiman semanya(Q S. Yunus [10]: 99)."

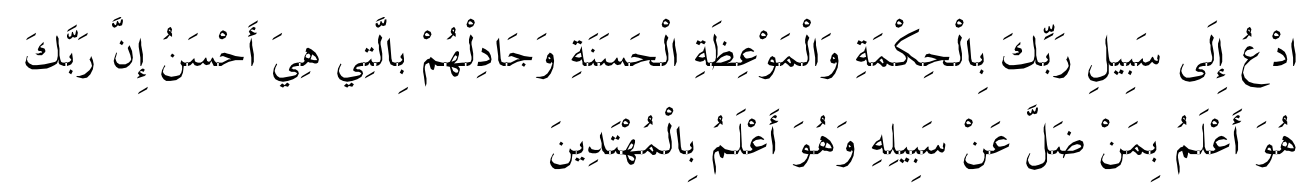

Serulah (manusia) kepadajalan Tuhanmu dengan hikmah dan pdajaran yangbaik dan bantablah merdka dangan cara yangbaik. Sesungghhnya Tuhanmu Dialahyangldihmengtahui tentangsiapa yangtesesat dari jalan-Nya dan Dialahyanglebihmengtahii orangforangyangmendapat petunjuk (Q.S. Al-Nahl [16]: 125)." 
Kata-kata hikmah/ kebijaksanaan itu memberikan ruang yang terbuka bagi pola hubungan di antara sesama anak bangsa, termasuk hubungan antaragama, antara etnis, suku atau budaya. Karena itu, fikih yang berasaskan nilai-nilai hikmah itu akan mudah menghargai perbedaan dan dinamika kehidupan bangsa, sebab fikih yang berasaskan nilai-nilai hikmah telah menetapkan "budaya yang sahih" sebagai basis pembentukan hukum fikih. Hal ini dikembangkan dari paradigma usul fikih multikultural yang memiliki orientasi mengedepankan pesan-pesan hukum kontekstual tanpa meninggalkan pesan-pesan hukum tekstual yang mendukung pembangunan kebidupan bermasyarakat dan berbangsa yang majemuk.

Paradigma usul fikih multikultural ini berusaha menempatkan nilai-nilai budaya dan memberikan kesempatan pada setiap generasi untuk memberikan terobosan baru untuk mencapai suatu pengetahuan hukum fikih yang aktual dan dinamis sesuai dengan kepentingan budaya masyarakat dan bangsa. Pertimbangan kepentingan budaya perlu memperoleh tempat yang layak. Bahkan titik berat proses pengambilan keputusan hukum fikih harus berpijak pada pertimbangan kepentingan budaya, sehingga dalam jangka panjang perlu ditinjau kemungkinan menyusun sistem hukum fikih yang berwawasan budaya, yakni fikih yang menghargai budaya masing-masing warga masyarakat.

Adapun contoh paradigma fikih yang mengabaikan kepentingan budaya tersebut dapat dilihat dari wacana fikih monokultural, misalnya dalam kasus fikih jinayat dan hukum kenegaraan yang dapat disebutkan, yaitu Pertama, hukum pidana ini membedakan warga negara berdasarkan agama dan gender. Misalnya, diyat(membayar kompensasi uang pada keluarga korban pembunuhan) jika korbannya perempuan atau non-Muslim tidak sebanyak diyatuntuk korban seorang laki-laki Muslim. Kedua, hukum fikih ini membedakan dejarat saksi berdasarkan jenis kelamin atau agama dalam masalah pembuktian. Kesaksian perempuan Muslim atau dhimmitidak diterima dalam kasus pelanggaran kriminal helud dan qistas Sementara itu, kesaksian seorang perempuan dalam urusan perdata dapat diterima dengan syarat, yakni dua orang perempuan untuk satu kasus persaksian. Ketiga, hukum perdata ini menetapkan adanya perbedaan dalam persoalan perceraian dan dhimmi>Seorang laki-laki Muslim dapat menikahi empat orang perempuan dalam waktu bersamaan dan juga dapat menceraikannya tanpa memberikan alasan apa pun, sedangkan perempuan Muslim hanya dapat menikah dengan satu orang laki-laki Muslim dan hanya bisa menuntut perceraian di 
ljtihad, Jurnal Wacana Hukum Islam dan Kemanusiaan, Vol. 12, No. 1, Juni 2012: 1-19

muka pengadilan. Selain itu, hukum perdata ini melarang perempuan Muslim menikah dengan laki-laki non-Muslim (An-Na'im, 1990: 89-91 dan Dahlan, 2009: 241-266).

D alam kasus pembangunan rumah ibadah, Said Aqil Siradj (2012) menunjukkan bahwa Al-Shaybani dalam bukunya al-Siyaral-Kabirmenjelaskan bahwa larangan membangun gereja baru berlaku jika kaum Muslimin menjadi mayoritas di wilayah tersebut. Alasannya, di daerah mayoritas itu, kaum Muslimin melakukan ibadah Shalat Jumat dan Idul Fitri. Mengizinkan mereka membangun gereja berarti memperlemah dan melawan kaum Muslimin secara formal. Namun demikian, jika non-Muslim menjadi mayoritas sehingga Shalat Jumat tidak diberlakukan, maka mereka tidak dilarang membangun gereja baru.

Dalam kasus keindonesiaan, Abdurrahman Wahid menunjukkan bahwa semua pihak perlu mewaspadai munculnya formalsasi syariat melalui pemberlakuan Peraturan Daerah (Perda) fikih yang tidak lagi sepenuhnya membawa pesan dan ajaran syariat, dan muatannya bersifat intoleran dan melanggar hak-hak sipil serta hak-hak minoritas karena diturunkan dari paradigma fikih yang sempit dan ekslusif. Bahkan ancaman nyata gerakan garis keras adalah usaha mengidentifikasi Islam dengan ideologi Wahabi/ Ikhwanul Muslimin serta usaha melenyapkan budaya dan tradisi bangsa ini serta menggantinya dengan budaya Wahabi yang diklaim oleh mereka sebagai budaya Islam. Ironisnya, agen-agen garis keras juga melakukan infiltrasi ke Majlis Ulama Indonesia (MUI). Bahkan MUI sekarang sudah menjadi bungker dan organisasi fundamentalis. Saat ini ada anggota MUI dan Hizbut Tahrir Indonesia (HTI) telah memainkan peran kunci dalam gerakan-gerakan garis keras di Indonesia. Padahal, HTI jelas-jelas mencita-citakan KhilafahIslamiyahyang secara ideologis bertentangan dengan Pancasila dan NKRI (Wahid, 2011: 160-162).

Sementara itu dalam ketentuan fikih multikultural ditegaskan bahwa persamaan kedudukan laki-laki dan perempuan harus ditegakkan di depan hukum. Demikian juga persamaan kedudukan non-Muslim di depan hukum, baik dalam persoalan hukum pidana, persaksian maupun perdata. Prinsip persamaan di depan hukum ini dirujukkan pada sumber asasi hukum fikih yang universal, bukan yang partikular, dalam kehidupan kenegaraan (An-Na'im, 1990: 180-181).

Nurcholish Madjid telah menunjukkan bahwa prinsip-prinsip egaliter dan kemajemukan hidup tersebut telah diberikan contoh oleh Nabi Muhammad saw. dalam bentuk "Piagam 
Madinah" untuk mengenalkan tatanan sosial-politik yang baik dengan mengenalkan sistem pendelegasian wewenang (artinya, wewenang tidak berpusat pada satu orang, melainkan melalui musyawarah) dan kehidupan berkonstitusi (artinya, sumber wewenang tidak ada pada keputusan pribadi, tetapi ada pada dokumen tertulis yang prinsip-prinsipnya disepakati bersama). Bahkan Al-Sayyid Muhammad Ma'ruf al-D awalibi dari Universitas Islam Internasional Paris menunjukkan bahwa Konstitusi Madinah itu menjadi dokumen yang memuat untuk pertama kalinya dalam sejarah, prinsip-prinsip dan kaidah-kaidah kenegaraan dan nilainilai kemanusaan yang sebelumnya tidak pernah dikenal umat manusia (Rachman, 1995: 590).

D alam kasus pembangunan rumah ibadah, Said Aqil Siradj (2012) menunjukkan bahwa Al-Sarakhsi dalam kitabnya al-Mabsut/menerangkan bahwa ahl al-dhimmah tidak dilarang sama sekali membangun gereja baru di desa. D engan demikian, hubungan Muslim dengan non-Muslim sekarang wajib dipandang sebagai anggota yang memiliki tanggung jawab terhadap keutuhan komunitas, sehingga Muslim sudah saatnya melakukan rekonstruksi dan kontekstualisasi terhadap pandangan fikih klasik, terutama mengenai pembangunan tempat ibadah di daerah mayoritas Muslim. Adapun larangan para ahli fikih klasik terhadap pembangunan gereja di daerah mayoritas Muslim itu pada dasamya lahir di tengah situasi antagonistik Islam dan agama lain, sedangkan kondisi masa kini dunia sudah berubah menuju kebersamaan.

D alam kasus keindonesiaan, fikih multikutlural bisa mengambil contoh kebijakan ulama pendiri negara bangsa ini yang menerima pencabutan "Piagam Jakarta" dari pembukaan UUD 1945 oleh Ki Bagus Hadikusumo, Kahar Mudzakir, Abikusno Tjokrosuyono, Ahmad Subardjo, Agus Salim dan KH A Wahid Hasyim (Wahid, 2006: 191-192). Kebijakan mereka yang menerima Pancasila dan pencabutan "Piagam Jakarta" dari Pembukaan UUD 45 menjadi tanda adanya sikap akomodatif mereka terhadap kemajemukan masyarakat dan bangsa Indonesia. Kebijakan ini jika dicari dalilnya dapat mendasarkan diri pada sabda Nabi Muhammad saw yang menyatakan bahwa "apa yang dipandang baik oleh kaum Muslimin, maka menurut Allah swt pun digolongkan sebagai perkara baik" (Zahrah, 1997: 417).

Contoh lain yang ditunjukkan oleh Abdurrahman Wahid adalah pembaruan fikih Syekh Arsyad yang berakar pada tradisi setempat, yakni pembaruan hukum fikih tentang hak kewarisan. D alam karyanya, Syekh Arsyad menyampaikan hukum Pexpatangan Hukum fikih ini memperharui hukum fikih pembagian hak kewarisan (faraiel) secara umum. Kalau biasanya 
dalam fikih itu disebutkan bahwa ahli waris laki-laki menerima bagian dua kali lipat dari ahli waris perempuan, Syekh Arsyad berpendapat bahwa ketentuan fikih waris itu berbeda dengan adat Banjar yang berlaku di daerah Kalimantan Tengah dan Kalimantan Selatan (Wahid, 2006: 250).

Wacana fikih multikultural tersebut sangat relevan jika dikaitkan dengan hasil penelitian Chanchal Kumar (2011:5) yang menunjukkan bahwa paham multikultural itu dapat menawarkan integrasi setiap individu ke dalam negara yang tidak didasarkan pada pelepasan total dari ikatan komunitas partikularistiknya. Sebaliknya, setiap individu dapat masuk ke dalam ikatan negara bangsa sebagai warga masyarakat yang majemuk, tetapi mereka tetap memiliki derajat setara, dan negara menjamin martabat setiap individu sebagai bagian integral dari martabat kolektif masyarakat. D engan kata lain, kelompok minoritas (non-Muslim) dan kaum perempuan dengan sifat partikularitasnya dapat bersinergi dengan tatanan hidup kemasyarakatan dan kebangsaan yang majemuk di Negara Kesatuan Republik Indonesia (NKRI), sehingga masing-masing kelompok dapat mengekspresikan hak-hak dan tanggung jawabnya dalam menjalani kehidupannya secara proporsional dan dinamis. Paradigma inilah yang hendak dibangun oleh paradigma "multikulturalitas dinamis".

\section{Penutup}

Paradigma usul fikih yang diperlukan saat ini adalah paradigma usul fikih multikultural, bukan paradigma usul fikih monokultural, yang memiliki beberapa karakteristik berikut: Pertama, ia menekankan pada pengambilan nilai-nilai budaya manusia sebagai prinsipnya dalam merumuskan hukum fikih, yakni mendasarkan diri pada ayat-ayat universal, bukan ayat-ayat partikular, untuk menangkap dan mengakomodasi keragaman kepentingan budaya manusia yang sahih. Kedua, ia mendorong kaum Muslim untuk selalu menangkap realitas aktual kekiniannya melalui pergeseran paradigma berpikir. Ketiga, ia berusaha menghargai dan menghormati adanya perbedaan gaya hidup beragama sebagai keniscayaan sebagai konter terhadap adanya gerakan formalisasi hukum fikih yang ekslusif dan sektarian di sejumlah daerah di Indonesia. 


\section{Daftar pustaka}

Abdullah, M. Amin, "Telaah Hermeneutis terhadap Masyarakat Muslim Indonesia”, dalam Muhammad Wahyuni Nafis (ed.). Kontekstualisas Ajaran Isam Jakarta: Paramadina, 1995.

Abdullah, M Amin. Studi Agama: Nomativitas dan Histaristas Yogyakarta: Pustaka Pelajar, 1996

al-Zukhaili, Wahbah. Usjalal-Fiqhal-Idami filid II. Beirut: D aæal-Fikr, 1986.

Arifin, Syamsul. SilangSengkanutAgama di RanahSosial TentangKonflik, KkerasanA gama dan Nalar Multikulturalisme Malang: UMM Press, 2009.

Baidoeri, Tadjoer Ridjal, "Ragam Reaksi Akulturatif Masuknya Ide-ide Baru dalam D unia Pesantren" dalam Makalahdisampaikan pada Lokakarya Nasional Pengasuh Pondok Pesantren se-Jawa Timur "Peningkatan Peran Pondok Pesantren dalam Membangun Budaya Damai”, 12-13 Agustus 2009 diselenggarakan oleh FAI Univ Darul 'Ulum Jombang Kerjasama dengan Puslitbang \& Diklat D epag RI.

Baraja, Abbas Arfan. Peran Tdkdh Agama DalamMereegh Dan Mengatas Konflik Hoizontal Bemuansa Sara (Suku, Agama, Ras \& Antar glongan), http:/ / blog.uin-malang.ac.id/ baraja/ 2011/ 03/ 12/ peran-tokoh-agama-dalam-mencegah-dan-mengatasi-konflikhorizontal-bernuansa-sara-suku-agama-ras-antar-golongan/ diakses tanggal 31 Maret 2012

Barton, G reg. GagasanIsamLiberal di Indonesia: PemikiranNe@ModenismeNurchdishMadjid, Djohan Efendi, Ahmad Wahid, dan Abdumahman Wahid terj. Nanang Tahqiq. Jakarta: Paramadina, 1999.

Baso, Ahmad, "Islam Liberal Sebagai Ideologi", Gebang Vol. 06, No 03, Pebruari-April 2000.

Dahlan, Moh. Abdullahi Ahmed An-Na'm: Epistemdog HukumIsam Yogyakarta: Pustaka Pelajar, 2009.

Dahlan, Moh. Epistemdog HukumIsam Studi Atas Penikiran Abdullahi Ahmed An-Näim Disertasi S-3 : UIN Sunan K alijaga Yogyakarta, 2006.

Djamil,Fathurahman. Filsafat HukumIsam Jakarta: Logos, 1997.

Fadjar, A Malik, "Strategi Pengembangan Pendidikan Islam di Era Globalisasi" dalam Seminar

Intermasional di EraGldbalisas: Tantangan danUpaya MeumuskanKerbali Oriettas Strateeg dan Kunikulum Kerjasama FAI-UMM dengan AIPUM Malaysia, di UMM, tgl 22-23 Juni 2007.

Faisol, Ahmad, "Rekonstruksi Sosial Masyarakat Lokal Sebagai Strategi Preventif Menanggulangi Terorisme", Salam Jumal Ilmtilmu Sosial, Vol 3 No.1, Januari-Juni 2010. 
ljtihad, Jurnal Wacana Hukum Islam dan Kemanusiaan, Vol. 12, No. 1, Juni 2012: 1-19

Fanani, Muhyar, "Sejarah Perkembangan Konsep Q at'i-Zanni: Perdebatan Ulama tentang Anggapan Kepastian dan Ketidakpastian Dalil Syari'at”, Al-Jawi'ah Vol. 39, No. 2, 2001.

Hanafi, Muchlis M, “Konsep al-Wasathiyyah dalam Islam” dalam Makalah disampaikan pada Lokakarya Nasional Pengasuh Pondok Pesantren se-Jawa Timur "Peningkatan Peran Pondok Pesantren dalam Membangun Budaya Damai", 12-13 Agustus 2009 diselenggarakan oleh FAI Univ Darul 'Ulum Jombang Kerjasama dengan Puslitbang \& Diklat D epag RI

Hasan, A hmad. TheEanty Deudqument of IsamicJunsprudene Islamabad: Islamic Research Institute, 1970.

http:/ / www.shaleholic.com.

al-Jassas, Abi Bakar Ahmad al-Razi. Ahkamal-Quranjilid II. Beirut: Dasal-Fikr, 1993.

K hallaf , 'Abd al-Wahhab. 'TlmUsłal al-Fiqh Kairo: D asal-Q alam, 1978.

K hun, Thomas S. TheStructureaf ScientificRedutions SecondEdition Chicago: The University of Chicago, 1970.

Kumar, Chanchal, "Multiculturalism in a Global Society: Minority Rights and Justice", Re serchonHumanitiesandSacial Scienes ISSN 2224-5766 (Paper) ISSN 2225-0484 (O nline), Vol.1, No.3, 2011, http:/ / www.iiste.org/ Journals/ index.php/ RHSS/ article/ view/ 1263, diakses tanggal 26 Maret 2012.

Kurzman, Charles (ed.). Wacana IsamLiberal: Penikiran IsamKontemporer tentangIsuIsuGlo bal. terj. Bahrul Ulum. Jakarta: Paramadina, 2001

Madjid, Nurcholish, "Pergeseran Pengertian "Sunnah" ke "Hadits" Implikasinya Dalam Pengembangan Syari'ah", dalam Budhy Munawar-Rachman (ed.). Kontakstualisas Ddktin IsamDalamSgarah Jakarta: Penerbit Yayasan Paramadina, 1995.

Mahmashani, Subhi, "Penyesuaian Fikih Islam dengan Kebutuhan Masyarakat Modem", dalam John J. D onohue dan John L. Esposito (peny.). Isamdan Penbanuan: Ensiklopedi Masalah-masalah terj. Machnun Husein, Jakarta: Rajawali Pers, 1995.

Minhaji, Akh., "Hak-hak Asasi Manusia dalam Hukum Islam: Ijtihad Baru tentang Posisi Minoritas Non-Muslim", dalam M. Amin Abdullah, dkk, (eds.). Antdog Studi Isam Yogyakarta: DIP PTA IAIN Sunan Kalijaga, 2000.

Minhaji, Akh., "Review Article: Mencari Rumusan Ushul Fiqh untuk Masa Kini”, Al-Jami'ah, No. 62, 2001.

Minhaji, Akh, "Hukum Islam: Antara Profanitas dan Sakralitas (Perspektif sejarah Sosial)", Pidato Pengukuhan Guru Besar pada Fak. Syari’ah UIN Sunan Kalijaga Yogyakarta, 2004. 
An-Na'im, Abdullahi Ahmed, "The Contingent Universality of Human Rights: The Case of Freedom of Expression in African and Islamic Contexts", EmoryIntemational Law Review11, 1997.

An-Na'im, Abdullahi Ahmed dan Francis M. Deng (eds.). Human Rights in Africa: Cross Cultural Pespetives Washington, D. C.: The Brookings Institution, 1990.

An-Na'im, Abdullahi A hmed. Tovardan IdamicReomation; Civil Libaties HumanRightsand International Law Syracuse: Syracuse University Press, 1990.

al-Q ardlawi, Yusuf. Madkhal li Dirashal-Syar'ahal-Idamiyah K airo: Maktabah Wahbah, 2001. Ricoeur, Paul. HemeneticsandtheHuman Saienes EssaysonLingrage, Adtion, andInterpreation, John B Thompson (terj. \& ed.). Cambridge: Cambridge University Press, 1982.

Rifai, Agus, "Perpustakaan dan Pendidikan Multikulturalisme" dalam Artikd PeetaLomba Penulisan Karya Ilmiah bag Pustakanan Tahun 2006, maungibdaam/ load/ 0-0-1-87-20, diakses terakhir tanggal 26 Maret 2012

Schumann, Olaf H. Menghadapi Tantangan, MempejuangkanKeukuman Jakarta: G unung Mulia, 2004.

al-Shawwaf, Muhami Munir Muhammad Thahir. Tahafut al-Qira'zh al-Mưałirah Cyprus: Al-Shawwaf li al-Nashr wa al-Dirasat, 1993.

Siradj, KH. Said Aqil, "Mengurai Kekusutan Keberagamaan", http:/ / www.wahidinstitute.org/ O pini/ D etail/ ?id=287/ hl=id/ Mengurai_Kekusutan Keberagamaan, diakses 31 Maret 2012.Al-Syafi'i, Muhammad bin I d̄ris. Al-Risala $\bar{h}$ Beirut: Dasal-Fikr, t. th.

Sirry, Mun'im A. SgarahFikihIsam Seanah Pengantar. Surabaya: Risalah Gusti, 1996.

Sjadzali, Munawir, "Kembali Ke Piagam Madinah", dalam Abu Zahra (ed.). Pditik Dem Tuhan: NasionalismeRdigusdi Indonesia, Jakarta: Pustaka Hidayah, 1999.

Suparlan, Parsudi, "Menuju MasyarakatIndonesiayang Multikultural”, Simposium Internasional Bali, Jurnal Antropologi Indonesia, D enpasar Bali, 16-21 Juli 2002 dikutip dari Mustato',

"Pendidikan Agama Islam Berbasis Multikultural”, Agustus 2008, dalam Arsip Blog

Syarifuddin, Amir. Ushul Fikih 1. Jakarta: Kencana, 2009.

Wahid, Abdurrahman, "Syari' atisasi dan Bank Syan'ah" dalam A bdurrahman Wahid. Isamku, IsamAnda, IsamKita: Agama Masjarakat Negara Demkkrasi. Jakarta: The Wahid Institute, 2006.

Wahid, Abdurrahman. Pergulatan Negara, Agama, dan Kedudayaan Jakarta: D esantara, 2001. Wahid, Abdurrahman. Sakadar Mendahului: Bungan Rampai Kata Pengantar. Jakarta: Penerbit Nuansa, 2011.

Zahrah, Muhammad Abu. Usul Fikih terj. Saifullah Ma'sum. Jakarta: Pustaka Firdaus, 1997. 